\title{
Translation and Interpreting in Disaster Situations
}

\section{Patrick Cadwell}

\section{INTRODUCTION AND DEFINITIONS}

Disasters affect the health and wellbeing of many people simultaneously in many different ways. People in a disaster may face life-threatening situations, become injured or disabled, lack essentials such as water, food, and shelter, become exposed to environmental pollution, or experience elevated psychosocial stress (Abrahams and Murray 2017). In order to respond to and recover from these effects and to reduce the future impact of similar situations, people need to communicate with each other (Coppola 2011). In a context of linguistic and cultural diversity, this communication may involve translation and interpreting (Federici 2016). Therefore, disaster settings can help us to understand more about translation and interpreting for global health.

Presenting a definition of disaster that is widely agreed upon is challenging; researchers and practitioners across various disciplines and occupations in the sciences, social sciences, humanities, and humanitarian sector adopt different perspectives on the concept (Perry 2007). Some have focused their definitions on scale - such as lives lost or damage incurred - and on the idea that the scale of a disaster must overwhelm those affected by it (Coppola 2011). Others have focused on hazards - events or conditions that have the potential to cause harm - and on associated risks and vulnerabilities, arguing that a risk of disaster exists only when someone or something that is vulnerable becomes 
exposed to a hazard (Birkmann 2013). Nowadays, scale or hazard alone are not considered sufficient to define disasters. There is broad agreement among researchers and practitioners that disasters should be defined as social phenomena (Perry 2007). Incidents such as disease outbreaks or tsunamis are not disasters in and of themselves; we consider them disasters only once the extent to which they disrupt the social world becomes clear. Consider the difference between a massive earthquake occurring in an isolated, uninhabited rural area and an earthquake of the same intensity occurring in an urban setting; the risk of disaster is higher in the latter because of the vulnerable people and property exposed to severe shaking. The United Nations Office for Disaster Risk Reduction or UNDRR (2017) foregrounds social aspects in its comprehensive definition of a disaster:

A serious disruption of the functioning of a community or a society at any scale due to hazardous events interacting with conditions of exposure, vulnerability and capacity, leading to one or more of the following: human, material, economic and environmental losses and impacts [...] The effect of the disaster can be immediate and localized, but is often widespread and could last for a long period of time. The effect may test or exceed the capacity of a community or society to cope using its own resources, and therefore may require assistance from external sources, which could include neighbouring jurisdictions, or those at the national or international levels. (UNDRR 2017: n.p.)

Researchers and practitioners sometimes use terms such as disaster, emergency, and crisis interchangeably; the conceptual field is somewhat unclear. For instance, the mission statement of the US Federal Emergency Management Agency involves '[h]elping people before, during, and after disasters' (see Department of Homeland Security 2019: 
n.p., my emphasis). Similarly, a recent emergency policy of the United Nations High Commissioner for Refugees or UNHCR is set down to deal with the onset of a crisis (see UNHCR 2017: n.p.).

Prominent definitions of crisis, disaster, and emergency indicate that these concepts share some common characteristics and that their interchangeable use may be justified at times. Sellnow and Seeger (2013: 4-20) identify three primary characteristics of a crisis: violated expectations, posed threats, and required responses. The definition of a disaster from UNDRR (2017) above is also based on response to a posed threat or hazard, however, it emphasises the severity of societal disruption that a disaster causes and does not limit the concept to unforeseen circumstances. Alexander's (2005) definition of an emergency is equally centred on responding to a threat. An emergency here is similar to a crisis in that it is usually unanticipated, but it is different from both a crisis and a disaster in that the rapidity of response required is worth noting. In short, when circumstances involve responding to a threat, the situation can be called a crisis, a disaster, or an emergency. Additionally, though, to emphasise the urgency and immediacy of the required response, use of the term emergency might be preferred, or to emphasise the scale and severity of societal disruption caused, use of the term disaster could be more effective.

At other times, some researchers and practitioners find it useful to more clearly differentiate types of disaster, emergency, and crisis. They use expressions such as natural or technological disaster, humanitarian crisis, or health emergency and define each one by the triggering hazard or potential effect involved (Coppola 2011; Perry 2007; UNDRR 2017). For instance, disasters arising from geological or meteorological 
processes, such as volcanic eruptions or hurricanes, are sometimes called natural disasters. Those triggered by circumstances other than natural processes, such as largescale transport accidents or chemical explosions, may be identified as technological disasters. Mass social disruptions arising from biological processes - such as Ebola or swine flu - can be categorised as health emergencies, while those triggered by conflict, insecurity, famine, drought, or mass migration may be labelled as humanitarian crises.

It is now less common to differentiate categories of disaster, and especially to separate natural from human-made disasters (Quarantelli 2000). This is to recognise the ways in which human decisions and activities influence and exacerbate geological, meteorological, biological, or migratory processes. The relationship between climate change and disaster is an issue of particular concern (Eiser et al. 2012). It is argued that all disasters are ultimately human-made. In addition, there continues to be debate over the extent to which intentional disruption to society brought about in situations of deliberate conflict should be included in conceptualisations of disaster (Quarantelli 2000). For instance, the UNDRR - an influential stakeholder - does not include armed conflict or social instability in its conceptualisation of the hazards that can lead to disaster (UNDRR 2017). Nevertheless, others acknowledge the place of conflict at the root of some disasters, labelling them complex emergencies (Coppola 2011). In short, this chapter focusses on disasters, however, the conceptual field in Disaster Studies is somewhat unclear, and circumstances that could be categorised as emergencies or crises may also be relevant.

Another terminological convention when discussing a disaster is to refer to its stakeholders using variations of two broadly encompassing terms: those 'affected' by the 
disaster and those 'responding' to it. At the same time, these concepts should not be separated rigidly, as the very first responders in a disaster are likely to be those directly affected as well, such as family, neighbours, or passers-by (Harvard Humanitarian Initiative 2011). In large-scale, international disasters, stakeholders involved in response and management can include: the state, civil institutions, and the military; nongovernmental and international governmental organizations, such as UN agencies and the International Federation of Red Cross and Red Crescent Societies; private sector organisations; ad hoc humanitarian groups; and diaspora communities living outside the affected state (UNDAC, 2018). It is also common in the study of disasters to specify a number of phases to anchor discussion, typically in a cyclical pattern along short-, medium-, and long-term timelines. Various models describe and explain these disaster timelines (Coppola 2011). Alexander (2002: 5) proposed a frequently-cited version comprising four phases: mitigation (to minimize future impacts of a disaster, e.g., through the formulation of particular building codes); preparedness (to reduce impending impacts of a disaster, e.g., through training populations at risk and other key stakeholders); response (to deal with the immediate aftermath of a disaster, e.g., through search and rescue activities); and recovery (to restore affected populations to normal life following a disaster, e.g., through the provision of temporary housing). This model represents a shift in thinking in Disaster Studies away from a reactive approach (where the timeline of a disaster starts at the onset of an event) to a proactive approach (where disasters are considered before the need to respond arises and the focus is on mitigating and preparing). 
The conceptual perspective on disaster adopted in this chapter is broad. The term disaster is used here to refer to any overwhelming social disruption - whatever the triggering hazard - with potential for serious, negative consequences, especially for the health and well-being of those affected. In addition, the terms 'stakeholder', 'mitigation', 'preparedness', 'response', and 'recovery' will all assist in the discussion that follows.

\section{IMPORTANCE OF LANGUAGE AND CULTURE IN DISASTER}

\section{SITUATIONS}

Many researchers who examine disasters, including those with a particular interest in health, argue for the importance of communication in disaster settings (see, e.g., Altay and Labonte 2014, Coombs 2012; Henrich and Holmes 2011; Holmes et al. 2009; Longstaff and Yang 2008; Tanner et al. 2009). Practitioners also recognise the operational and strategic importance of information and communication (see, e.g., ActionAid 2012; Slade 2011; World Health Organization 2012), especially through wideranging, international agreements and structures, such as the Sendai Framework for Disaster Risk Reduction 2015-2030 (Aitsi-Selmi et al. 2016) or the European Union's General Guidelines for Operational Priorities on Humanitarian Aid (European Commission 2018). While it is clear that communication in disasters is a valued object of enquiry, can the same be said of languages and cultures through which disaster-related communication is mediated?

The likelihood of disasters striking culturally and linguistically diverse populations is increasing, and those involved in disaster communication need to account 
for this diversity. Recent studies of disaster management indicate that, while fewer lives are being lost each year to disaster, the number of disasters and the number of people affected by them annually are both rising, with the world's poorest citizens being disproportionately affected (Coppola 2011). Human societies are becoming concentrated around large-scale urban environments (Smith 2013), and long-term displacement of populations - driven especially by political insecurity and conflict - add increasing complexity to disaster settings (IDMC 2018). In the future, therefore, there will be more disasters forcing large-scale movements of diverse groups to and from already-diverse mega-cities.

Clear, timely, accurate, and reliable information is essential for communication in a disaster to succeed (Coyle and Meier 2009). Despite recognition of the importance of these features of communication in research on disasters (see, e.g., Fischer 2008; Haddow, Bullock, and Coppola 2017; Tierney and Waugh 2007), and despite acknowledgment in the literature of the need for effective communication throughout all phases of disaster situations (Comfort 2007; Kapucu 2006; Kendra and Wachtendorf 2003), researchers and practitioners have so far overlooked or downplayed the potential negative consequences when those involved in a disaster have limited or no understanding of each other's languages and cultures (Moser-Mercer, Kherbiche, and Class 2014; Nepal et al. 2012; O’Brien et al. 2018). Moreover, core texts in Disaster Studies mention language, culture, translation or interpreting either only briefly and without critical discussion (e.g., Rodríguez, Quarantelli, and Dynes 2006) or not at all (e.g., Drabek 2003, 2010; Quarantelli 1987). 
Recent research has begun to affirm that the effectiveness of disaster operations is reduced when diverse language needs are not considered and that benefits accrue when linguistic and cultural issues are taken into account. Research has indicated that those affected by a disaster can misunderstand risks and make poor decisions when communicating in a language they do not understand well (McKee 2014; SantosHernández and Hearn Morrow 2013). The accessibility and effectiveness of information throughout all phases of a disaster are contingent on the information being provided in an appropriate linguistic and cultural frame (Nsiah-Kumi 2008; Purtle, Siddiqui, and Andrulis 2011). Linguistic and cultural barriers can hinder participation in response and recovery as well as mitigation and preparedness efforts (see, e.g., Kirsch, Sauer, and Sapir 2012; Koenig 2013). In particular, linguistic and cultural barriers risk excluding disaster-affected communities from these efforts, cutting off valuable sources of in-depth local knowledge and information (Munro 2013). Some researchers and practitioners have identified lack of translation as a perennial hidden issue in disaster-related communication (Harvard Humanitarian Initiative 2011). Influential stakeholders, such as the International Federation of Red Cross and Red Crescent Societies, acknowledge that multilingual communication strategies in disaster situations around the world - where they exist - are limited and rarely based on appropriate evidence concerning real language needs:

However linguistically diverse the affected population, humanitarian responses are usually coordinated in international lingua francas and delivered in a narrow range of national languages. Basic data on the languages and literacy levels of the affected population is not systematically collected and shared in the way that other fundamental characteristics such as gender and age might be. As a result, evidence- 
based multilingual communication strategies are rarely developed. (Fisher et al. 2018: 103)

An incapacity to understand the language in which disaster-related information is disseminated is a key marker of social vulnerability and is often accompanied by a lack of established social networks, lack of experience of disaster events, inability to access key resources due to physical and social isolation, and poor socio-economic conditions (Ogie et al. 2018).

Operational effectiveness is not the only reason to argue for consideration of language, culture, and their mediation in disaster situations. Rights-based or ethics-based arguments can also be made. Greenwood et al. (2017) assert that information and the methods of its communication are basic humanitarian rights that should constitute alongside other rights, such as the right to protection, privacy, or security - the foundation of humanitarian activities before, during, and after a disaster. O'Brien et al. (2018) acknowledge this and further argue that language, as a trait, should not prevent entitlement to other fundamental rights or be a cause for discrimination. They apply this claim to the provision of translation and interpreting in disaster communication and find support for it in milestone documents, such as the United Nations' Universal Declaration of Human Rights (United Nations 1948) and the European Union Charter of Fundamental Rights (Council of the European Union 2008). Moreover, Geale (2012) argues that consideration of language and culture in disasters, especially the languages and cultures of those directly affected, are central to achieving the ethical principles of equity, justice, dignity, and fairness that should guide disaster management. 


\section{VIEWS ON TRANSLATION AND INTERPRETING IN DISASTERS}

Various communicative strategies could be adopted to respond to the linguistic and cultural needs outlined above. For instance, an approach based on plurilingualism could encourage the learning and use of multiple languages by key stakeholders (see, e.g., Clerveaux, Spence, and Katada 2010 for an introduction to this idea). This approach could range from learning key vocabulary or phrases to undertaking more comprehensive language instruction. Given the time, resources, and motivation required to learn another language, researchers are focussing on creative, targeted, flexible, and low-resource acquisition methods, for instance, through gamification. Allied to language learning could be the use of a small number of vehicular languages - such as English, French, or a dominant regional language - in disaster situations (see, e.g., Fisher et al. 2018 for discussion of this phenomenon). Additionally, a lingua franca or dominant language in a disaster setting could be simplified and controlled to make it more accessible to greater numbers of people with some grasp of the language (see, e.g., Carroll 2012 for debates around simplification). Alternatively, conventional language could be abandoned, and pictographs or symbols could be used to satisfy the communicative needs of diverse groups (see, e.g., Sahana Software Foundation 2019 for an outline of preliminary research). These are all valid communicative strategies; however, they do not entail interlingual translation and interpreting. Nevertheless, as the following will show, interlingual and intercultural translation and interpreting have been used to respond to diverse communicative needs in many disaster situations. 
Researchers in Turkey - a country with significant exposure to hazards including earthquakes, floods, and landslides - carried out pioneering work on the experiences, needs, and training of interpreters in disasters there (Bulut and Kurultay 2001; Doğan 2016; Doğan and Kahraman 2011; Kurultay and Bulut 2012). The 2010 Haiti Earthquake was another turning point in the study of translation and interpreting in disasters. At the time, Haitian diaspora, along with technologically-proficient volunteer organisations based outside of Haiti, translated text messages, created maps and person-finder tools, and built machine translation engines (Lewis 2010; Lewis, Munro, and Vogel 2011; Munro 2013). Successive disasters in New Zealand and Japan in 2010-2011 formed the basis of further research. Studies centred on: the lived experience of translation and interpreting (Cadwell 2015); the work of community interpreters (Naito 2012); best practice guidelines highlighting the value of training and skill (Wylie 2012); interpreting services on television in the aftermath of these disasters (McKee 2014); and the use of information and communication technology for translation and interpreting (Cadwell and O'Brien 2016). Translation and interpreting in conflict zones and military operations have also been objects of considerable enquiry (see, e.g., Kelly and Footitt 2012; MoserMercer, Kherbiche, and Class 2014; Salama-Carr 2007; Snellman 2016). Moreover, practitioners have conducted valuable research to illustrate the contributions and challenges of translation and interpreting in disaster settings. Chief among these is Translators without Borders, a non-profit organisation whose goal is to ensure the appropriateness and availability of understandable humanitarian content. The organisation achieves this goal by providing translations and language technology solutions in areas of crisis relief, health, and education to other non-profit and aid 
organisations (Translators without Borders 2019). It also trains translators and interpreters and promotes the importance of language in humanitarian work (ibid.). It has produced a number of detailed reports on its crisis relief operations in various earthquakes, conflicts, and disease outbreaks (ibid.).

Researchers and practitioners particularly interested in health have also carried out studies involving translation and interpreting in disasters. A body of research presents recommendations on how medical teams can work effectively with translators and interpreters (e.g., Bolton and Weiss 2001; Powell and Pagliara-Miller 2012) and on how parties involved can manage the physical and mental health risks and ethical dilemmas associated with disaster settings (e.g., Athey and Moody-Williams 2003; Greenstone 2010; Shiu-Thornton et al. 2007). These studies tend to focus on the responder side - the health professionals or the interpreters and translators - and only a limited number of studies approach issues of health, disaster, and translation or interpreting from the side of the disaster-affected population (e.g., Hanson-Easey et al. 2018; O'Brien and Cadwell 2017). This means that existing research findings related to disaster may not encourage healthcare decisions that respect the needs, preferences, and values of patients sufficiently.

Much of the research cited above consists of small studies supported by relatively small amounts of empirical data. It is therefore difficult to draw broad, generalised conclusions based on these studies. Nonetheless, certain features of translation and interpreting can be discerned that are common across many of the research contexts involved. These include the ad hoc, local, and voluntary nature of the activities and the importance of cultural issues to the communication. 


\section{Ad hoc, local, voluntary, and culture-centred}

In many disaster contexts, translation and interpreting were carried out in an ad hoc, uncoordinated manner and on a voluntary basis by local groups of affected people who had linguistic proficiency and cultural knowledge, and often not any formal training (Bulut and Kurultay 2001; Cadwell 2015; Federici and Cadwell 2018; Lewis, Munro, and Vogel 2011; Moser-Mercer, Kherbiche, and Class 2014; Munro 2013; Wylie 2012). One reason proposed for the ad hoc, bottom-up nature of these efforts is that the pool of trained translators and interpreters in the languages required in contemporary disaster situations is limited (Fisher et al. 2018). Translation and interpreting efforts required in disaster situations at the time of writing include, for instance, Rohingya, Tamasheq, or Tigrinya (ICRC 2019), none of which is available as a search option on the widely used database of language professionals, ProZ.com (https://www.proz.com/). Therefore, structures for the systematic and professional provision of services in and out of the required languages and cultures are already un- or underdeveloped before a disaster strikes.

Local grassroots endeavours can sometimes hold high personal stakes for the translators and interpreters concerned; as members of the disaster-affected population, they may have a special interest in some of the disaster-related information they mediate. While this can lead to feelings of stress and potential traumatisation, translators and interpreters in disaster settings also report positive psychological effects through engaging proactively and communally with disaster-related information (McKee 2014).

The voluntary basis of much disaster translation and interpreting is taken here to mean that the individuals concerned offer their time and effort to help others without 
compensation (Erickson 2012). However, compensated, trained professionals also contribute to disaster translation and interpreting activities. It should be remembered that acting as a volunteer does not preclude being a professional (O'Hagan 2011), and professional interpreters and translators volunteered their time in many disaster settings (see, e.g., Bulut and Kurultay 2001; Cadwell 2015; Munro 2013; Wylie 2012). Nevertheless, these professional efforts have been somewhat limited in scope and direction and have frequently taken place in the context of large, international humanitarian organizations using a dominant lingua franca of the humanitarian sector (Fisher et al. 2018; Moser-Mercer, Kherbiche, and Class 2014). Ad hoc, local, and voluntary translation and interpreting efforts are valuable. Nonetheless, such efforts can lead to inefficiencies. Uncoordinated local volunteers working spontaneously may needlessly reproduce information that has already been translated elsewhere or may fail to recognise the translation and interpreting tasks that are needed most. For instance, a lack of coordinated translations in the 2018 monsoon season in Bangladesh led the Rohingya community there to feel that they lacked sufficient information in their language about flood safety, while having adequate information about other topics, such as health or security (Marzotto 2019).

In addition to the ad hoc, local, and voluntary aspects of much disaster translation and interpreting, it is important to emphasise the significance of intercultural issues in disaster situations. Disasters are characterised by and experienced within varying contexts of cultural beliefs and world views that influence vulnerabilities, risk interpretations, preparedness and response decisions, and other forms of information processing (e.g., Cornia, Dressel and Pfeil 2016; Eiser et al. 2012; Harro-Loit, Vihalemm, 
and Ugur 2012). There are many possible definitions of translation and interpreting. (For an overview of core ideas and debates, see, e.g., House 2018; Munday 2016; Pym 2014). Not all of these definitions include consideration of culture. However, definitions of disaster translation and interpreting should include culture as a key defining characteristic. For example, since 2017, the New Zealand Red Cross has been coordinating a project to involve residents of the Wellington Region from diverse linguistic and cultural backgrounds in the translation of earthquake-preparedness guides for recent migrants. Certain cultural concepts of disaster preparedness in New Zealand that were unproblematic for longer-terms residents - such as, working bees (voluntary groups set up for a charitable goal) or camping (the items and practices to lodge safely outdoors) - proved challenging for recent migrants to New Zealand to understand (Federici and Cadwell 2018; Shackleton 2018). Conduct of this project has caused coordinators to question some cultural assumptions of disaster preparedness communication in a New Zealand context (Shackleton 2018).

In sum, there is a substantial amount of evidence to suggest that studying disasters can deepen our understanding of translation and interpreting. At the same time, existing scholarship in Translation and Interpreting Studies can inform our understanding of disaster situations. Research on non-professional interpreting and translation practices (e.g., Antonini 2017; Pérez-González and Susam-Saraeva 2012), community translation and interpreting (e.g., Taibi and Ozolins 2016; Valero-Garcés and Tipton 2017), and the functioning and motivation of global communities of linguistic volunteers (e.g., McDonough Dolmaya 2012; Olohan 2014) are particularly relevant to describing and explaining communicative phenomena observed in disasters. Various directions are 
possible for future research. However, it is possible to indicate a number of critical issues on which future efforts could focus.

\section{CRITICAL ISSUES AND FUTURE DIRECTIONS}

Disaster situations cause us to examine the ethics of translation and interpreting. They have much to tell us about the training of linguistic and cultural volunteers, whether these are professional or non-professional translators or interpreters. Disasters also cause us to consider appropriate modalities for the delivery of linguistically and culturally mediated information, and raise important issues about the relationship between policy and practice in translation and interpreting.

\section{Ethics}

Some scholars argue that issues arising from translation or interpreting encounters are not just practical but fundamentally ethical (e.g., Baker and Maier 2011; Goodwin 2010). Disaster situations affirm this and provide the basis for complex examinations of ethical questions for all those involved, including those who translate and interpret (O'Mathúna et al. 2020). Not all translation and interpreting in a disaster situation will be carried out in the immediate response phase: the shift to a proactive paradigm in Disaster Studies implies the need for consideration of longer timelines that focus on translation and interpreting in the recovery as well as mitigation and preparedness phases. Therefore, while disaster translators and interpreters will always have limited resources, time will not always be a limiting factor. Time for ethical thinking can and should be found in disaster settings. Indeed, even in situations where time is of the essence (e.g., emergency 
rooms in hospitals or in the immediate response phase of a disaster), those involved are trained in advance and given support afterwards in how to make and deal with complex ethical decisions quickly. Disaster translators or interpreters could benefit from such training and support to enable them to cope with complex ethical situations.

People who translate or interpret in disaster situations sometimes question what they ought to do, as well as the rightness or wrongness of their actions (Businaro 2012). Ethical questions in disaster translation and interpreting relate to issues of quality and accuracy, neutrality and bias, fairness and marginalisation, and the prudent use of limited resources in disasters (see, e.g., Hanson-Easey et al. 2018; McKee 2014; Moser-Mercer, Kherbiche, and Class 2014). Let us imagine some of the challenging questions that a translator or interpreter or someone who manages translation or interpreting in a disaster may be confronted with:

Is the quality of translation or interpretation that will be produced in a high-stress, highly constrained environment good enough to be of use?

Should translation or interpreting proceed if the translator or interpreter is not confident that they will produce accurate texts?

Can and should a translator or interpreter be impartial if the disaster-related information affects them directly?

Will translating or interpreting for one linguistic/cultural group put other groups who have no-one translating or interpreting for them at further disadvantage? Is the priority of translation or interpreting high enough to take limited resources away from another disaster preparedness or response need? 
None of these questions has an obvious answer, and translators and interpreters and those who manage such activities would benefit from assistance in resolving such ethical dilemmas. One strategy - based on the principle of beneficence - is popular in healthcare settings, and especially in relation to the ethics of medical research in disasters; it involves balancing the potential benefits and likely harms of a particular action before making a decision (Beauchamp 2019). Another strategy - the deontological approach has been to propose principles that guide ethical decision-making; codes of ethics put forward by associations of professional translators and interpreters illustrate this approach (Lambert 2018). A further strategy - developed from virtue ethics - encourages personal integrity and the development of character traits such as honesty and courage to promote ethical behaviour (O’Mathúna et al. 2020). While translators, interpreters, and those who manage their activities might find these strategies useful, it is first important that they know about them. Some university-level courses for translators and interpreters have introduced ethical training onto their curricula (see, e.g. Baker and Maier 2011; Drugan and Megone 2011). Including disasters as cases studied in these curricula could help prepare disaster translators and interpreters of the future. However, as many disaster translators and interpreters are untrained volunteers who provide their services ad hoc, mechanisms for ethical support outside of traditional academic and professional settings are still required. Designing and testing mechanisms to provide ad hoc ethical support for translators and interpreters in disasters should be a matter of priority. 


\section{Training}

Training on topics beyond ethics alone is another critical issue, especially to support those who volunteer. There is a widespread perception in the literature on volunteering of ‘...good-hearted, well-meaning volunteers doing important and challenging work but with little training or accountability' (Erickson 2012: 167). Systematic, scalable models of training that can be delivered at short notice in self-sustaining ways are required for disaster situations (Moser-Mercer, Kherbiche, and Class 2014). Researchers at the InZone Project at the University of Geneva have carried out pioneering work to develop innovative, technology-supported training for multilingual communication in conflict and crisis settings (InZone 2019). Other initiatives to design and deliver training in the fundamentals of translation for culturally and linguistically diverse communities engaged in disaster-related translation projects have also been developed and evaluated (Federici and Cadwell 2018). Moreover, mechanisms involved not only in the training but also in the recruitment, coordination, and motivation of linguistic volunteers are of critical importance for disaster translation and interpreting. Work has begun to examine existing successful models of linguistic volunteer training and management, and apply them to disaster settings (Cadwell, Bollig, and Ried 2019).

\section{Modalities}

It is also of critical importance for researchers and practitioners involved in disasterrelated translation and interpreting to consider appropriate modes of delivery for translated and interpreted communication. It may be reasonable to assume that a need for interpreting will be greatest at the response phase of a disaster immediately following the 
onset of an event when the situation is rapidly changing. In contrast, translation will make a greater contribution at the preparedness or recovery phases of disaster when timelines are longer, the situation is more stable, and communication may not involve spontaneous, face-to-face interactions to the same extent. Nonetheless, a strict dichotomy between translation and interpreting activities in disaster settings might not be useful. Phenomena such as sight-translation, translation dictation, and audiovisual translation already establish fluidity between the modal boundaries of translated information (see, e.g., Kaindl 2013). Furthermore, a body of research (Fu et al. 2010; Nsiah-Kumi 2008; Yip et al. 2013) indicates that translated texts in disaster situations should be delivered not only in written format but also orally through alternative channels such as community or faithbased centres. Doing so takes into account issues such as literacy, accessibility, and cultural norms when communicating with older adults, children, those with physical or mental disabilities, or other particularly vulnerable groups. Technology also has an important function to perform here. Researchers have begun to examine how technology can assist in the generation of culturally and linguistically appropriate communication for and by diverse groups in disaster settings through, for instance, crowdsourcing, machine translation, or other novel forms of information processing, distribution, and translation (Lewis, Munro, and Vogel 2011; Munro 2013; Ogie et al. 2018; Sutherlin 2013; Tanaka et al. 2007). More work exploring the intersection between technology, modality, translation, and interpreting is required in disaster contexts. 


\section{Policies}

A final issue of critical importance is that of public policy. Governments make disasterrelated policies to protect the public from the impacts of disasters and to improve the public's resiliency to future disasters (Birkland 2016). Policies are an expression of what the government views as problems and the actions they intend to take or not to take when confronted with these problems (Birkland 2011). Research carried out on a small sample of national governments (in Ireland, the U.K., New Zealand, Japan and the U.S.A.) has indicated that several of them have yet to develop translation and interpreting significantly as tools in their disaster management policies (O’Brien et al. 2018). Without sufficient recognition of translation and interpreting as problems in need of solutions in disaster situations, responsibilities will remain unclear, funding will not be allocated, and detailed plans cannot be actualised. Following a disaster, a process of learning may take place leading to the formation of new policy (Birkland 2011). However, Gerber (2007) cautions that this learning may not always occur, or occur sufficiently, especially if there is a lack of political will. A critical issue for researchers and practitioners interested in translation and interpreting in disaster situations, therefore, is to advocate to key stakeholders - especially those holding political power - for the benefits of enshrining translation and interpreting in public policies on disasters.

\section{CONCLUSION}

The study of translation and interpreting in disaster situations is worthwhile, especially because the future is likely to bring more disasters involving large-scale displacements of 
diverse groups. It may be difficult to define a disaster clearly: any overwhelming social disruption with potential for serious, negative consequences, especially for the health and well-being of those affected, could probably be termed a disaster. Whatever the label used, it is widely agreed that clear, timely, accurate, and reliable communication is vital in such situations. Much research up to now overlooked or downplayed the roles of language, culture, translation, and interpreting in achieving this communication.

Nevertheless, other research indicated that consideration of these factors in disaster communication is important to avoid misunderstanding of risks, improve decisionmaking, encourage participation of disaster-affected communities, access in-depth local knowledge, recognise a human right to accessible information, and achieve equity, justice, and dignity. Analysis in this chapter of research about disasters in Turkey, Haiti, New Zealand, Japan, Kenya, Bangladesh, and elsewhere revealed certain common characteristics of translation and interpreting in these settings. These include the ad hoc, local, and voluntary nature of the activities and the importance of cultural issues to the communication. In future research on translation and interpreting in disaster situations, it could be useful to examine other critical issues. In particular, ethics, training, communication modality, and public policy in relation to disaster translation and interpreting are matters of interest.

\section{FURTHER READING}

Federici, Federico M. (2016). Mediating Emergencies and Conflicts: Frontline Translating and Interpreting. London: Palgrave Macmillan. 
This book brings together fieldwork and analysis from a variety of disaster situations, health emergencies, and conflicts to underline the need for adequate language mediation in these settings. It reviews a broad range of literature from relevant domains and introduces theoretical concepts for the study of disaster translation and interpreting.

Translators without Borders. (2015). Words of Relief: Ebola Crisis Learning Review. [online] Available at: https://translatorswithoutborders.org/wpcontent/uploads/2015/10/20150529-Ebola-Learning-Review_FINAL.pdf [Accessed 28 May 2019].

This report examines a non-profit organisation's efforts to improve communication with people affected in West Africa in the Ebola outbreak of 2014 and 2015. It focuses on practice and provides a useful overview of key issues involved in translation and interpreting when disaster strikes.

Munro, Robert. (2013). Crowdsourcing and the Crisis-Affected Community: Lessons Learned and Looking Forward from Mission 4636. Journal of Information Retrieval, 16(2): 210-266.

This academic article uses the example of the 2010 earthquake in Haiti to focus on translation in disaster settings and especially on the intersection between human 
translation efforts - largely carried out by volunteers - and enabling technologies, such as mobile phones, social media, and the Internet.

Moser-Mercer, Barbara, Kherbiche Leïla, and Class Barbara. (2014). Interpreting

Conflict: Training Challenges in Humanitarian Field Interpreting. Journal of Human

Rights Practice, 6(1): 140-158.

This academic article focuses on interpreting in conflicts and disasters and argues for the importance of sustainable and scalable training as a solution to linguistic mediation needs.

\section{RELATED TOPICS}

community/liaison interpreting; remote (telephone) interpreting; sign language interpreting; child language brokering; ethics of translation in healthcare settings;

translation in global epidemics

\section{REFERENCES}

Abrahams, Jonathan and Murray, Virginia. (2017). Health Emergency and Disaster Risk Management: Overview. [online] Available at: http://www.who.int/hac/techguidance/preparedness/who-factsheet-overviewdecember2017.pdf?ua=1 [Accessed: 28 May 2019].

ActionAid. (2012). ActionAid/infoasaid Learning Review of the Pilot Communications Project in Isiolo. [online] Available at: http://actionaid.org/sites/default/files/isiolo_learning_review__final_oct_2012_0.pdf [Accessed: 28 May 2019]

Aitsi-Selmi, Amina, Murray, Virginia, Wannous, Chadia, Dickinson, Chloe, Johnston, David, Kawasaki, Akiyuki, Stevance, Anne-Sophie, and Yeung. Tiffany. (2016). 
Reflections on a Science and Technology Agenda for 21st Century Disaster Risk Reduction. International Journal of Disaster Risk Science, 7(1): 1-29.

Alexander, David. (2002). Principles of Emergency Planning and Management. Oxford: Oxford University Press.

Alexander, David. (2005). Towards the Development of A Standard in Emergency Planning. Disaster Prevention and Management, 14(2): 158-175.

Altay, Nezih and Labonte, Melissa. (2014). Challenges in Humanitarian Information Management and Exchange: Evidence from Haiti. Disasters, 38(s1): S50-S72.

Antonini, Rachele. 2017. Non-Professional Interpreting and Translation: State of the Art and Future of an Emerging Field of Research. Amsterdam: John Benjamins Publishing Company.

Athey, Jean and Moody-Williams, Jean. (2003). Developing Cultural Competence in Disaster Mental Health Programs: Guiding Principles and Recommendations. Washington, DC: US Department of Health and Human Services.

Baker, Mona and Maier, Carol. (2011). Ethics in Interpreter and Translator Training: Critical Perspectives. The Interpreter and Translator Trainer, 5(1): 1-14.

Beauchamp, Tom. (2019). The Principle of Beneficence in Applied Ethics. In: Zalta, Edward N. (ed.) The Stanford Encyclopedia of Philosophy (Spring 2019 Edition). [online] Available at: https://plato.stanford.edu/archives/spr2019/entries/principle-beneficence/ [Accessed 28 May 2019].

Birkland, Thomas A. (2011). An Introduction to the Policy Process: Theories, Concepts, and Models of Public Policy Making, $3^{\text {rd }}$ ed., Armonk, NY: Sharpe.

Birkland, Thomas A. (2016). Policy Process Theory and Natural Hazards. In: Oxford Research Encyclopedia of Natural Hazard Science. [online] Available at: https://oxfordre.com/naturalhazardscience/view/10.1093/acrefore/9780199389407 .001.0001/acrefore-9780199389407-e-75 [Accessed 28 May 2019].

Birkmann, Jörn. (2013). Measuring Vulnerability to Natural Hazards: Towards Disaster Resilient Societies. Tokyo: United Nations University Press.

Bolton, Paul and Weiss, William. (2001). Communicating across Cultures: Improving Translation to Improve Complex Emergency Program Effectiveness. Prehospital and Disaster Medicine, 16(4): 252-256.

Bulut, Alev and Kurultay, Turgay. (2001). Interpreters-in-Aid at Disasters: Community Interpreting in the Process of Disaster Management. The Translator, 7(2): 249263.

Businaro, Roberta. (2012). Relief Operations across Language Barriers: The Interpreter Factor. Master's dissertation. University College Dublin.

Cadwell, Patrick. (2015). Translation and Trust: A Case Study of How Translation was Experienced by Foreign Nationals Resident in Japan for the 2011 Great East Japan Earthquake. PhD thesis. Dublin City University.

Cadwell, Patrick and O'Brien, Sharon. 2016. Language, Culture, and Translation in Disaster ICT: An Ecosystemic Model of Understanding. Perspectives, 24(4): 557-575.

Cadwell, Patrick, Bollig, Claudia, and Ried, Julia. (2019). Management and Training of Linguistic Volunteers: A Case Study of Translation at Cochrane Germany. In: 
Federici, Federico M. and O’Brien, Sharon (eds.) Translation in Cascading Crises. Milton Park, Abingdon: Routledge.

Carroll, Tessa. 2012. Multilingual or Easy Japanese? Promoting Citizenship via Local Government Websites. In: Gottlieb, Nanette (ed.) Language and Citizenship in Japan. New York: Routledge: 193-216.

Clerveaux, Virginia, Spence, Balfour, and Katada, Toshitaka. (2010). Promoting Disaster Awareness in Multicultural Societies: The DAG Approach. Disaster Prevention and Management, 19(2): 199-218.

Comfort, Louise K. (2007). Crisis Management in Hindsight: Cognition, Communication, Coordination, and Control. Public Administration Review, 67(s1): 189-197.

Coombs, W. Timothy. (2012). Crisis Communication and Its Allied Fields, In: Coombs, W. Timothy and Holladay, Sherry J. (eds.) The Handbook of Crisis Communication. Chichester, West Sussex: John Wiley \& Sons: 54-64.

Coppola, Damon P. (2011). Introduction to International Disaster Management, $2^{\text {nd }}$ ed. Boston: Butterworth-Heinemann.

Cornia, Alessio, Dressel, Kerstin, and Pfeil, Patricia. (2016). Risk Cultures and Dominant Approaches towards Disasters in Seven European Countries. Journal of Risk Research, 19(3): 288-304.

Council of the European Union. (2008). Charter of Fundamental Rights of the European Union. Paris: Éditions BIOTOP.

Coyle, Diane and Meier, Patrick. (2009). New Technologies in Emergencies and Conflicts: The Role of Information and Social Networks. Washington, D.C. and London, UK: UN Foundation-Vodafone Foundation Partnership.

Department of Homeland Security. (2019). FEMA: About the Agency. [online] Available at: https://www.fema.gov/about-agency [Accessed: 7 August 2019].

Doğan, Aymil. (2016). Anybody Down There? Emergency and Disaster Interpreting in Turkey. In: Federici, Federico M. (ed.) Mediating Emergencies and Conflicts: Frontline Translating and Interpreting. London: Palgrave Macmillan: 44-53.

Doğan, Aymil and Kahraman, Rana. (2011). Emergency and Disaster Interpreting in Turkey: Ten Years of a Unique Endeavour. Hacettepe University Journal of Faculty of Letters, 28(2): 61-76.

Drabek, Thomas E. (2003). Strategies for Coordinating Disaster Responses. Boulder, CO: Institute of Behavior Sciences.

Drabek, Thomas E. (2010). The Human Side of Disaster. Boca Raton: CRC Press.

Drugan, Joanna and Megone, Chris. (2011). Bringing Ethics into Translator Training: An Integrated, Inter-disciplinary Approach. The Interpreter and Translator Trainer, 5(1): 183-211.

Eiser, Richard J., Bostrom, Ann, Burton, Ian, Johnston, David M., McClure, John, Paton, Douglas, van der Pligt, Joop, and White, Mathew P. (2012). Risk Interpretation and Action: A Conceptual Framework for Responses to Natural Hazards. International Journal of Disaster Risk Reduction. 1: 5-16.

Erickson, Jennifer. (2012). Volunteering with Refugees: Neoliberalism, Hegemony, and (Senior) Citizenship. Human Organization, 71(2): 167-175.

European Commission. (2018). Commission Staff Working Document: General Guidelines on Operational Priorities for Humanitarian Aid in 2019. [online] 
Available at: https://ec.europa.eu/echo/sites/echo-site/files/ggophafinal.pdf [Accessed: 28 May 2019].

Federici, Federico M. (2016). Mediating Emergencies and Conflicts: Frontline Translating and Interpreting. London: Palgrave Macmillan.

Federici, Federico, M. and Cadwell, Patrick. (2018). Training Citizen Translators: Design and Delivery of Bespoke Training on the Fundamentals of Translation for New Zealand Red Cross. Translation Spaces, 7(1): 23-43.

Fischer, Henry (2008). Response to Disaster, $3^{\text {rd }}$ ed., Lanham: University Press of America.

Fisher, David, Hagon, Kirsten, Lattimer, Charlotte, O'Callaghan, Sorcha, Swithern, Sophia, and Walmsley, Lisa. (2018). World Disasters Report 2018: Leaving No One Behind. Geneva, Switzerland: International Federation of Red Cross and Red Crescent Societies.

Fu, King-Wa, White, James, Chan, Yuen-Ying, Zhou, Ling, Zhang, Qiang, and Lu, Qibin. (2010). Enabling the Disabled: Media Use and Communication Needs of People with Disabilities during and after the Sichuan Earthquake in China. International Journal of Emergency Management, 7(1): 75-87.

Geale, Sara Kathleen. (2012). The Ethics of Disaster Management. Disaster Prevention and Management, 21(4): 445-462.

Gerber, Brian J. (2007). Disaster Management in the United States: Examining Key Political and Policy Challenges. Policy Studies Journal, 35(2): 227-238.

Goodwin, Phil. (2010). Ethical Problems in Translation, The Translator, 16(1): 19-42

Greenstone, James. L. (2010). Use of Interpreters with Crisis Intervention Teams, Behavioral Health Units, and Medical Strike Teams: Responding Appropriately and Effectively. International Journal of Emergency Mental Health, 12(2): 7982.

Greenwood, Faine, Howarth, Caitlin, Escudero Poole, Danielle, Raymond, Nathaniel A., and Scarnecchia, Daniel P. (2017). The Signal Code: A Human Rights Approach to Information During Crisis. [online] Available at:

https://hhi.harvard.edu/publications/signal-code-human-rights-approachinformation-during-crisis [Accessed: 28 May 2019].

Haddow, George D., Bullock, Jane A. and Coppola, Damon P. (2017). Introduction to Emergency Management. Amsterdam: Elsevier.

Hanson-Easey, Scott, Every, Danielle, Hansen, Alana, and Bi, Peng. (2018). Risk Communication for New and Emerging Communities: The Contingent Role of Social Capital. International Journal of Disaster Risk Reduction, 28: 620-628.

Harro-Loit, Halliki, Vihalemm, Triin, and Ugur, Kadri. (2012). Cultural Experience as a (Critical) Factor in Crisis Communication Planning. Journal of Contingencies and Crisis Management, 20(1): 26-38.

Harvard Humanitarian Initiative. (2011). Disaster Relief 2.0: The Future of Information Sharing in Humanitarian Emergencies. Washington, D.C. and Berkshire, UK: UN Foundation \& Vodafone Foundation Technology Partnership.

Henrich, Natalie and Holmes, Bev J. (2011). Communicating during a Pandemic: Information the Public Wants about the Disease and New Vaccines and Drugs. Health Promotion Practice, 12(4): 610-619. 
Holmes, Bev. J., Henrich, Natalie, Hancock, Sara, and Lestou, Valia. (2009). Communicating with the Public during Health Crises: Experts' Experiences and Opinions. Journal of Risk Research, 12(6): 793-807.

House, Juliane. (2018). Translation: The Basics. London and New York: Routledge.

ICRC (International Committee of the Red Cross). (2019). Languages and Interpreting Working with Us. [online] Available at: https://www.icrc.org/en/who-weare/jobs/languages-profiles [Accessed: 28 May 2019].

IDMC (Internal Displacement Monitoring Centre). (2018). Global Report on Internal Displacement 2018. [online] Available at: http://www.internaldisplacement.org/global-report/grid2018/ [Accessed: 28 May 2019.

InZone. (2019). Who We Are. [online] Available at: https://www.unige.ch/inzone/whowe-are/ [Accessed 28 May 2019].

Kaindl, Klaus. (2013). Multimodality and Translation. In: Millán, Carmen and Bartrina, Francesca (eds) The Routledge Handbook of Translation Studies. Milton Park, Abingdon: Routledge: 257-269.

Kapucu, Naim. (2006). Examining the National Response Plan in Response to a Catastrophic Disaster: Hurricane Katrina in 2005. International Journal of Mass Emergencies and Disasters, 24(2): 271-299.

Kelly, Michael, and Hilary Footitt. (2012). Languages and the Military: Alliances, Occupation and Peace Building. Basingstoke: Palgrave Macmillan.

Kendra, James M. and Wachtendorf, Tricia. (2003). Elements of Resilience after the World Trade Center Disaster: Reconstituting New York City's Emergency Operations Centre. Disasters, 27(1): 37-53.

Kirsch Thomas, Sauer, Lauren, and Guha Sapir, Debarati. (2012). Analysis of the International and US Response to the Haiti Earthquake: Recommendations for Change. Disaster Medicine and Public Health Preparedness, 6(3): 200-208.

Koenig, Kristi L. (2013). Adventures in Disaster Medicine: A United States Experience that Illustrates Key Public Health Policy Principles. Journal of Acute Medicine, 3(4): 119-124.

Kurultay, Turgay and Bulut, Alev. (2012). Re-Evaluating Community Interpreting: Emergency and Disaster Interpreting. I. U. Journal of Translation Studies, 3(6): 23-43.

Lambert Joseph. (2018). How Ethical are Codes of Ethics? Using Illusions of Neutrality to Sell Translations. Journal of Specialised Translation, 30: 269-290.

Lewis, William. (2010). Haitian Creole: How to Build and Ship an MT Engine from Scratch in 4 Days, 17 Hours, \& 30 Minutes. In: Proceedings of the 14th Annual Conference of the European Association for Machine Translation (EAMT 2010) Saint-Raphaël, France, 27-28 May: no pagination.

Lewis, William, Munro, Robert, and Vogel, Stephan. (2011). Crisis MT: Developing a Cookbook for MT in Crisis Situations. In: Proceedings of the 6th Workshop on Statistical Machine Translation, Edinburgh, Scotland, 30-31 July: 501-511.

Longstaff, Patricia H. and Yang, Sung-Un. (2008). Communication Management and Trust: Their Role in Building Resilience to 'Surprises' such as Natural Disasters, Pandemic Flu, and Terrorism. Ecology and Society, 13(1): 3. [online] http://www.ecologyandsociety.org/vol13/iss1/art3/ [Accessed 28 May 2019]. 
Marzotto, Mia. (2019). The Language Factor: Lessons for Communication and Community Engagement from Translators without Borders' Experience. [online] Available at: https://odihpn.org/magazine/language-factor-lessonscommunication-community-engagement-translators-without-borders-experience/ [Accessed 8 August 2019].

McDonough Dolmaya, Julie. (2012). Analyzing the Crowdsourcing Model and Its Impact on Public Perceptions of Translation. The Translator, 18(2): 167-191.

McKee, Rachel. (2014). Breaking News: Sign Language Interpreters on Television during Natural Disasters. Interpreting, 16(1): 107-130.

Moser-Mercer, Barbara, Kherbiche Leïla, and Class Barbara. (2014). Interpreting Conflict: Training Challenges in Humanitarian Field Interpreting. Journal of Human Rights Practice, 6(1): 140-158.

Munday, Jeremy. (2016). Introducing Translation Studies: Theories and Applications, $4^{\text {th }}$ ed., London, New York: Routledge.

Munro, Robert. (2013). Crowdsourcing and the Crisis-Affected Community: Lessons Learned and Looking Forward From Mission 4636. Journal of Information Retrieval, 16(2): 210-266.

Naito, Minoru. (2012). Community Interpreting at the Time of Great East Japan Earthquake. Interpretation and Translation, 14(1): 97-115.

Nepal, Vishnu, Banerjee, Deborah, Perry, Mark, and Scott, Deborah. (2012). Disaster Preparedness of Linguistically Isolated Populations: Practical Issues for Planners. Health Promotion Practice, 13(2): 265-271

Nsiah-Kumi, Phyllis A. (2008). Communicating Effectively with Vulnerable Populations during Water Contamination Events. Journal of Water and Health, 6(s1): 63-75.

O'Brien, Sharon and Cadwell, Patrick. (2017). Translation Facilitates Comprehension of Health-Related Crisis Information: Kenya as an Example. JoSTrans: The Journal of Specialised Translation, (28): 23-51.

O’Brien, Sharon, Federici, Federico, M., Cadwell, Patrick, Marlowe, Jay, and Gerber, Brian. (2018). Language Translation during Disaster: A Comparative Analysis of Five National Approaches. International Journal for Disaster Risk Reduction, 31: 627-636.

Ogie, Robert, Castilla Rho, Juan, Clarke, Rodney J., and Moore, Alison. (2018). Disaster Risk Communication in Culturally and Linguistically Diverse Communities: The Role of Technology. Proceedings, 2(19): 1256.

O’Hagan, Minako. (2011). Community Translation: Translation as a Social Activity and Its Possible Consequences in the Advent of Web 2.0 and Beyond. In: O'Hagan, Minako (ed.) Translation as a Social Activity: [Community Translation 2.0]. Brussels: University Press Antwerp: 111-128.

Olohan, Maeve. (2014). Why Do You Translate? Motivation to Volunteer and TED Translation. Translation Studies, 7(1): 17-33.

O’Mathúna, Dónal P., Parra Escartín, Carla, Roche, Proinsias, and Marlowe, Jay. (2020). Engaging Citizen Translators in Disasters: Exploring Ethical Challenges.

Translation and Interpreting Studies. 
Pérez-González, Luis and Susam-Sarajeva, Şebnem. (2012). Non-Professionals Translating and Interpreting: Participatory and Engaged Perspectives. The Translator, 18(2): 149-165.

Perry, Ronald W. (2007). What is a Disaster? In: Rodríguez, Havidán, Quarantelli, Enrico L., and Dynes, Russell R. (eds.) Handbook of Disaster Research. New York: Springer: 1-15.

Powell, Clydette and Pagliara-Miller, Claire. (2012). The Use of Volunteer Interpreters during the 2010 Haiti Earthquake: Lessons Learned from the USNS COMFORT Operation Unified Response Haiti. American Journal of Disaster Medicine, 7(1): 37-47.

Purtle, Jonathan, Siddiqui, Nadia J., and Andrulis, Dennis P. (2011). Language Issues and Barriers. In: Penuel, K. Bradley and Statler, Matthew (eds.) Encyclopedia of Disaster Relief. Thousand Oaks, California: Sage Publication: 379-382.

Pym, Anthony. (2014). Exploring Translation Theories, $2^{\text {nd }}$ ed., London and New York: Routledge.

Quarantelli, Enrico L. (1987). The Social Science Study of Disasters and Mass Communications. Newark, Delaware: Disaster Research Center, University of Delaware.

Quarantelli, Enrico. L. (2000). Disaster Research. In: E. Borgatta \& R. Montgomery (eds.), Encyclopedia of Sociology Vol. 1, $2^{\text {nd }}$ ed., New York: Macmillan: 682-688.

Rodríguez, Havidán, Quarantelli, Enrico. L., and Dynes, Rusell. (2006). Handbook of Disaster Research. New York: Springer.

Sahana Software Foundation. (2019). People with Literacy Challenges are 'Left Behind' in Disaster Communication. [online] Available at: https://www.elrha.org/projectblog/people-with-literacy-challenges-are-left-behind-in-disaster-communication/ [Accessed 28 May 2019].

Salama-Carr, Myriam. (2007). Translating and Interpreting Conflict. Amsterdam: Rodopi.

Santos-Hernández, Jenniffer M. and Hearn Morrow, Betty. (2013). Language and Literacy. In: Brenda D. Phillips, Deborah S.K. Thomas, Lovekamp, William E., and Fothergill, Alice (eds.) Social Vulnerability to Disasters, $2^{\text {nd }}$ ed., Boca Raton, London and New York: CRC Press: 265-280.

Sellnow, Timothy L. and Seeger, Matthew W. (2013). Theorizing Crisis Communication. Chichester, West Sussex: Wiley-Blackwell.

Shackleton, Jamie. (2018). Preparedness in Diverse Communities: Citizen Translation for Community Engagement. In: K. Stock and D. Bunker (eds.), Proceedings of ISCRAM Asia Pacific 2018, Auckland, New Zealand: Massey University: 400406.

Shiu-Thornton, Sharyne, Balabis, Joseph, Senturia, Kirsten, Tamayo, Aracely, and Oberle, Mark. (2007). Disaster Preparedness for Limited English Proficient Communities: Medical Interpreters as Cultural Brokers and Gatekeepers. Public Health Reports, 122(4): 466-471.

Slade, Diana. (2011). Communication for Health in Emergency Contexts: Final Report. Strawberry Hills, N.S.W.: Australian Learning and Teaching Council. 
Smith, Keith. (2013). Environmental Hazards: Assessing Risk and Reducing Disaster, $6^{\text {th }}$ ed., Milton Park, Abingdon, Oxon: Routledge.

Snellman P. (2016). Constraints on and Dimensions of Military Interpreter Neutrality. Linguistica Antverpiensia, 15: 260-281.

Sutherlin, Gwyneth. (2013). A Voice in the Crowd: Broader Implications for Crowdsourcing Translation during Crisis. Journal of Information Science, 39(3): 397-409.

Taibi, Mustapha and Ozolins, Uldis. (2016). Community Translation. London: Bloomsbury Academic.

Tanaka, Shozo, Miyao, Masaru, Okamoto, Kohei, and Hasegawa, Satoshi. (2007). Template Translation for Multilingual Disaster Information System. In: Kaneda, Yukio, Kawamura, Hiroshi, and Sasai, Masaki (eds.) Frontiers of Computational Science. Berlin, Heidelberg: Springer-Verlag: 353-356.

Tanner, Andrea, Friedman, Daniela B., Koskan, Alexis and Barr, Daphney. (2009). Disaster Communication on the Internet: A Focus on Mobilizing Information. Journal of Health Communication, 14(8): 741-755.

Tierney, Kathleen J. and Waugh, William L. (2007). Emergency Management: Principles and Practice for Local Government. Washington, D.C.: ICMA Press.

Translators without Borders. (2019). Crisis Response: Words of Relief. [online] Available at: https://translatorswithoutborders.org/our-work/crisis-response/ [Accessed 28 May 2019].

United Nations. (1948). The Universal Declaration of Human Rights. [online] Available at: http://www.un.org/en/universal-declaration-human-rights/ [Accessed 28 May 2019].

UNDAC (United Nations Disaster Assessment and Coordination Team). (2018). UNDAC Field Handbook, $7^{\text {th }}$ ed., Geneva: United Nations.

UNDRR (United Nations Office for Disaster Risk Reduction). (2017). Terminology: Disaster. [online] Available at: https://www.unisdr.org/we/inform/terminology\#letter-d [Accessed: 28 May 2019].

UNHCR (United Nations High Commissioner for Refugees). (2017). UNHCR's New Emergency Policy: How to Better Prepare for and Respond to the Needs of Displaced People. [online] Available at: https://www.refworld.org/cgibin/texis/vtx/rwmain?docid=59d4d5354 [Accessed: 7 August 2019].

Valero Garcès, Carmen, and Tipton, Rebecca. (2017). Ideology, Ethics and Policy Development in Public Service Interpreting and Translation. Bristol: Multilingual Matters.

World Health Organization. (2012). Toolkit for Assessing Health-System Capacity for Crisis Management. Copenhagen: World Health Organization, Regional Office for Europe.

Wylie, Sarah. (2012). Best Practice Guidelines for Engaging with Culturally and Linguistically Diverse (CALD) Communities in Times of Disaster. Christchurch, New Zealand: Christchurch City Council.

Yip, Mei Po, Ong, Brandon, Meischke, Hendrika, Feng, Sherry X., Calhoun, Rebecca, Painter, Ian, and Tu, Shin-Ping. (2013). The Role of Self-Efficacy in 
Communication and Emergency Response in Chinese Limited English Proficiency LEP Populations. Health Promotion Practice, 14(3): 400-407. 


\section{BIOGRAPHICAL NOTE}

Patrick Cadwell is an assistant professor of Translation Studies at the School of Applied Language and Intercultural Studies in Dublin City University. His current research centres on the impact of translation and interpreting on experiences of crisis, disaster, community, and development. He focuses especially on trust, terminology, and ad-hoc translation. 